\title{
Biometric Portraits of Emperors on the Roman Coins
}

\section{Amelia Carolina Sparavigna}

Politecnico di Torino, Italy

\begin{abstract}
Here we want to show that the Romans used some biometric measurements when they struck the portraits of their Emperors on coins. That is, the Roman coins were made considering some measurements to give a truthful portrait of the Roman leaders.
\end{abstract}

Keywords: Portraitures of Julius Caesar, Augustus, Tiberius, Caligula, Titus, Trajan, Marcus Aurelius, Pantelleria heads, Coins.

Written in Torino, 20 August 2018. Submitted Zenodo. DOI: 10.5281/zenodo.1400577

In two recent papers [1,2] we have shown an excellent agreement between the profiles of two marble portraits of Julius Caesar - Pantelleria and Tusculum - and a coin of $44 \mathrm{BC}$, struck just after Caesar's refusal of the crown offered by Mark Antony during the Lupercalia [3]. Of the two marble portraits of Caesar we discussed also in [4-6].

In the Figure 1 we can see how the comparison was made in [1]. On the left, it is shown the coin; in the middle it is given the profile of the marble head found in Pantelleria. On the right, the two profiles (coin profile in blue and marble head profile in red) are shown as being superimposed. Note please the coincidence of them.
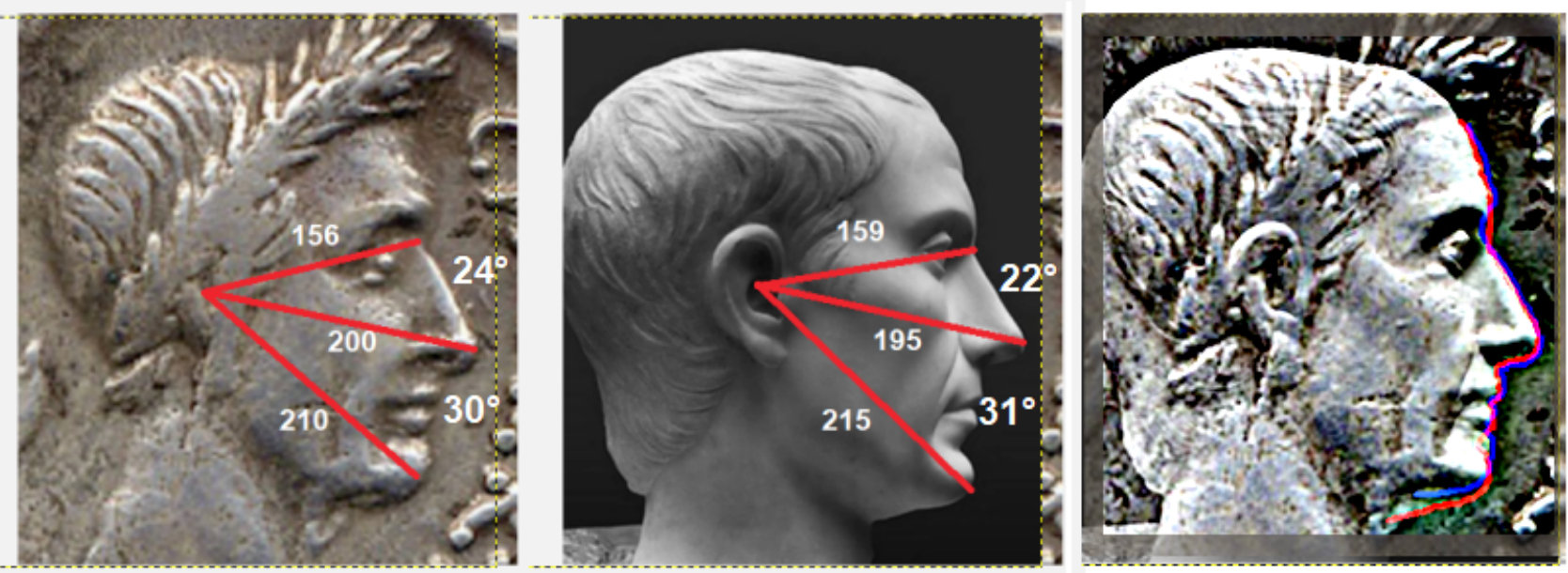

Figure 1. Profiles of coin and marble head (Pantelleria) of Julius Caesar. The profiles are the same as we can see in the right panel. Images of coin and bust are used here just for scientific and cultural purposes. Since the position of the ear seems the same, we can use for comparison the distances as given by the number of pixels between the end points. (Courtesy images. Coin: Macquarie University, Sidney, Australia. Marble head: Pinterest, unknown author). 
From the Figure 1, we can see that, besides the profile, even the position of the ear seems to be the same. Therefore, let us measure the lengths of three segments: from the ear to the nasal bridge (ENB), from the ear to the tip of the nose (ETN) and from the ear to the tip of the chin (ETC). Let us give these distance is pixels. For the coin, ENB=156, ETN=200, $\mathrm{ETC}=210\left(\right.$ angles $\left.24^{\circ}, 30^{\circ}\right)$. Here the ratios ENB / ETN $=0.78, \mathrm{ETC} / \mathrm{ETN}=1.05$.

For the marble head $E N B=159, E T N=195, E T C=215$. Here the ratios $E N B / E T N=0.81$, ETC $/$ ETN $=1.10$ (angles $\left.22^{\circ}, 31^{\circ}\right)$. Differences of the ratios of lengths are very small, less than $5 \%$.

In $[1,2]$, we wrote that a possible conclusion was the following. The Tusculum and the Pantelleria portraits are in good agreements to the coin of $44 \mathrm{BC}$, which was struck when Caesar was alive, one month before his assassination. As a consequence, these busts are the most faithful rendering of Caesar's head. Here, we want to consider another important fact, and it is the following. The Romans used in coins some biometric parameters; that is, their coins were considering some measurements of distances to give a truthful portrait of the Roman leaders. Probably, the measures are those given here as the lengths from the ear to the nasal bridge (ENB), from the ear to the tip of the nose (ETN) and from the ear to the tip of the chin (ETC), and by the angles between the above mentioned segments.

To support the use of biometric parameters by the Romans, let us give other comparisons between coins and statues, besides that shown in the Figure 1. Let us consider the portraits of Augustus (actually, we use the pictures of the statues as the pictures of real persons).
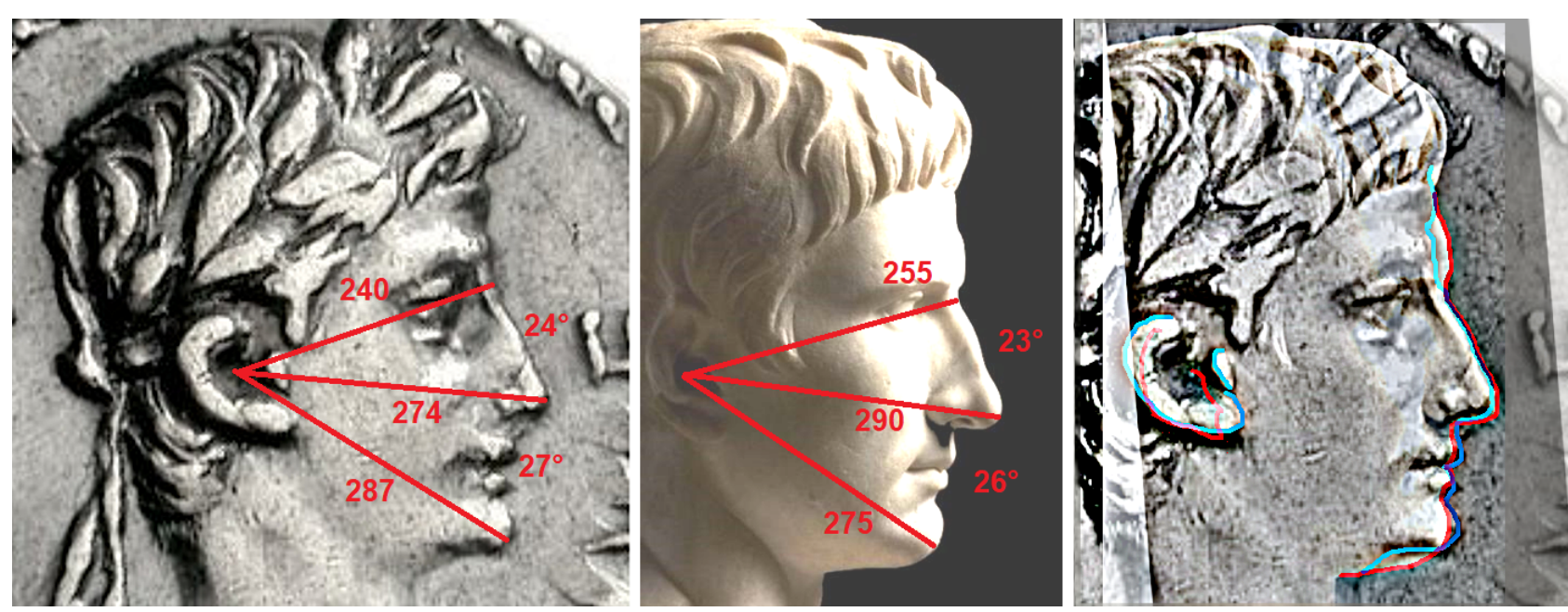

Figure 2. Profiles of coin and marble head (British Museum) of Augustus. Measurements are given in pixels. Images of coin and bust are used here just for scientific and cultural purposes. (Courtesy images. Coin: CNG for Wikipedia, marble head: British Museum). The coin is an AR Denarius. from Lugdunum (Lyon) mint. 
Born Gaius Octavius Thurinus (23 September 63 BC - 19 August AD 14), Augustus was a Roman statesman and military leader, defined as the first Emperor of the Roman Empire. He ruled the Imperial Rome from $27 \mathrm{BC}$ until his death in AD 14.

Here in the Figure 2 his profile in a coin and in a statue.

For the coin, ENB $=240, \mathrm{ETN}=274, \mathrm{ETC}=287\left(\right.$ angles $\left.24^{\circ}, 27^{\circ}\right)$. Here the ratios ENB $/$ $\mathrm{ETN}=0.88, \mathrm{ETC} / \mathrm{ETN}=1.05$. For the marble head $\mathrm{ENB}=255, \mathrm{ETN}=290, \mathrm{ETC}=275$ (angles are $23^{\circ}, 26^{\circ}$ ). Here the ratios ENB $/ \mathrm{ETN}=0.88$, ETC $/ \mathrm{ETN}=0.95$. Differences of the ratio EBN / ETN are negligible, but of ETC / ETN are of about $10 \%$.

On the right of the Figure 2, the two profiles (coin profile in blue and marble head profile in red) have been superimposed.
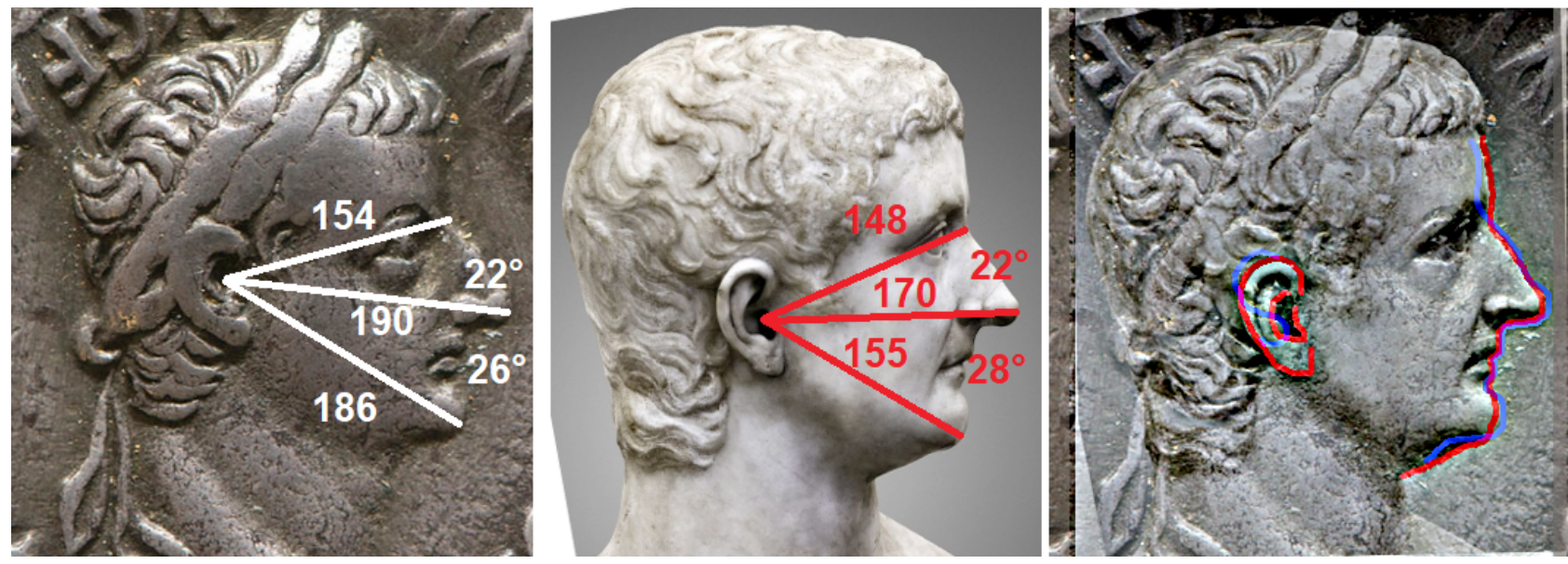

Figure 3. Profiles of coin and marble head of Tiberius. Length are given in pixels. Images of coin and bust are used here just for scientific and cultural purposes. (Courtesy images. Coin. Credit: York Museums Trust (Yorkshire Museum). Marble head: Museo Archeologico di Napoli. Credit: !Storax).

Let us continue with Tiberius.

Tiberius Claudius Nero (16 November 42 BC - 16 March 37 AD) was Roman emperor from $14 A D$ to $37 A D$, succeeding the first emperor, Augustus. He was born to Tiberius Claudius Nero and Livia Drusilla in a Claudian family. His mother divorced Nero and married Octavian, that is, Augustus, who officially became his stepfather. Later, Tiberius had been adopted by Augustus. Through the adoption, he officially became a Julian, assuming the name Tiberius Julius Caesar. The subsequent emperors after Tiberius would continue this blended dynasty of both families for the following thirty years; historians have named it the Julio-Claudian dynasty.

Here data concerning Tiberius (see Figure 3). For the coin, ENB =154, ETN $=190, \mathrm{ETC}=$ 186 (angles $22^{\circ}, 26^{\circ}$ ). Here the ratios ENB $/ \mathrm{ETN}=0.81, \mathrm{ETC} / \mathrm{ETN}=0.98$. For the 
marble head $\mathrm{ENB}=148, \mathrm{ETN}=170, \mathrm{ETC}=155$ (angles are $22^{\circ}, 2^{\circ}$ ). Here the ratios $\mathrm{ENB} /$ $\mathrm{ETN}=0.87, \mathrm{ETC} / \mathrm{ETN}=0.91$. Differences of the ratios are less than $7.5 \%$.

On the right of the Figure 3, the two profiles (coin profile in blue and marble head profile in red) have been superimposed.

The coincidence of the profiles is not so perfect as in the case of Caesar and Augustus, but probably this is due to the angle of view that the statues has in the picture.

After Tiberius, Caligula became emperor.

Gaius Julius Caesar Augustus Germanicus (31 August 12 - 24 January 41 AD) was Roman emperor from AD 37 to AD 41. He was the son of Germanicus, a popular Roman general, and Agrippina the Elder (granddaughter of Augustus), Caligula was born into the first ruling family of the Roman Empire, conventionally known as the Julio-Claudian dynasty. Two years after Caligula's birth, Germanicus' uncle and adoptive father, Tiberius, succeeded Augustus as emperor of Rome in AD 14.
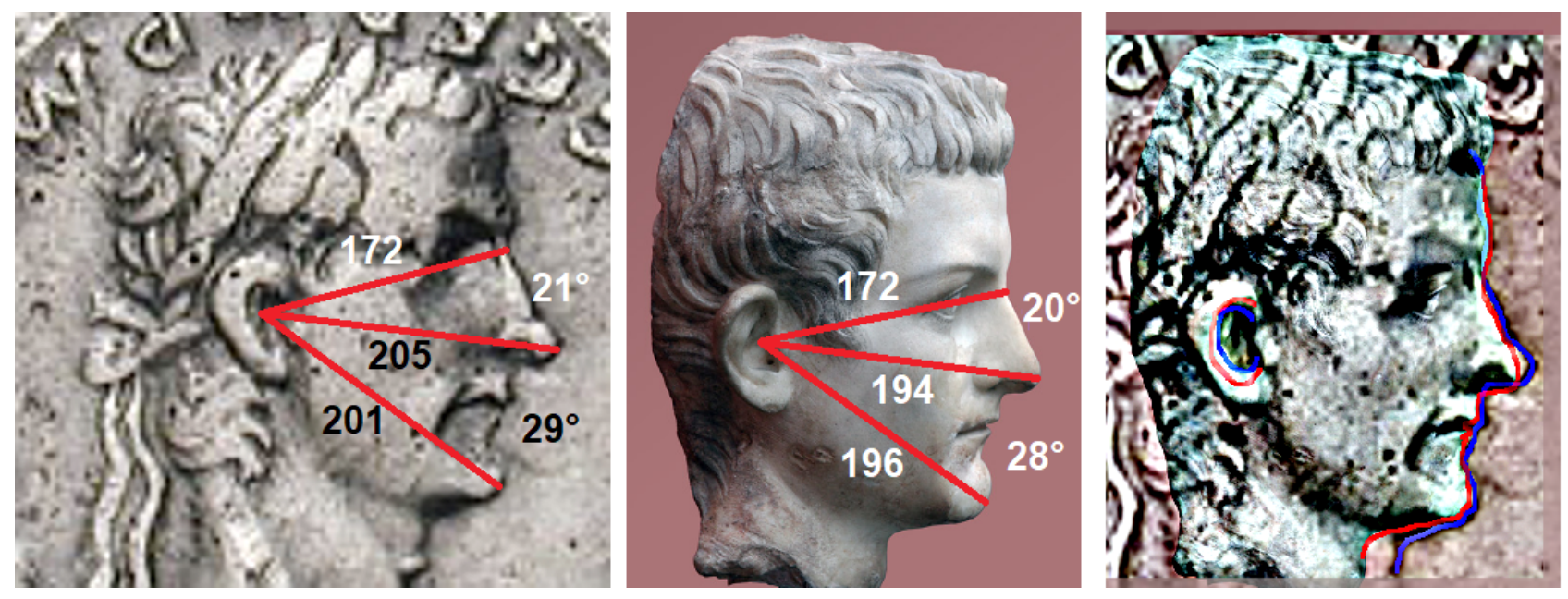

Figure 4. Profiles of coin and marble head of Caligula. Length are given in pixels. Images of coin and bust are used here just for scientific and cultural purposes. (Courtesy images. Coin. Credit: CNG Coins. Marble head: Ny Carlsberg Glyptotek in Copenhagen. Credit: Roger Ulrich).

Here data concerning Caligula (see Figure 4). For the coin, ENB $=172, \mathrm{ETN}=205, \mathrm{ETC}=$ 201 (angles $21^{\circ}, 29^{\circ}$ ). Here the ratios ENB / ETN $=0.84$, ETC $/$ ETN $=0.98$. For the marble head $\mathrm{ENB}=172, \mathrm{ETN}=194, \mathrm{ETC}=196$ (angles are $20^{\circ}, 28^{\circ}$ ). Here the ratios $\mathrm{ENB} /$ $\mathrm{ETN}=0.88, \mathrm{ETC} / \mathrm{ETN}=1.01$. Differences of the ratios are less than $5 \%$.

Let us continue with an example from Flavian dinasty: emperor Titus.

Titus Flavius Caesar Vespasianus Augustus (30 December 39 - 13 September 81 AD) was Roman emperor from 79 to $81 \mathrm{AD}$. As previously told, he was a member of the Flavian dynasty, succeeding his father Vespasian upon his death. Actually he was the first Roman emperor to come to the throne after his own biological father. 
For the head of Titus we will use a drawing created after a picture in [7]. In this reference, they are shown and discussed the three marble heads found in 2003 in Pantelleria, representative of Julius Caesar, Titus and Agrippina. Sebastiano Tusa, Thomas Schaefer (Tubingen University) and Massimo Osanna (Università della Basilicata) are the researchers that discovered them. Among these three marble heads, that of Caesar is the most famous, and it is the one that we used for the comparison given by Figure 1.

The coin that we use here is a denarius depicting Titus, c. 79. The reverse of the coin commemorates his triumph in the Judaean wars, representing a Jewish captive kneeling in front of a trophy of arms.

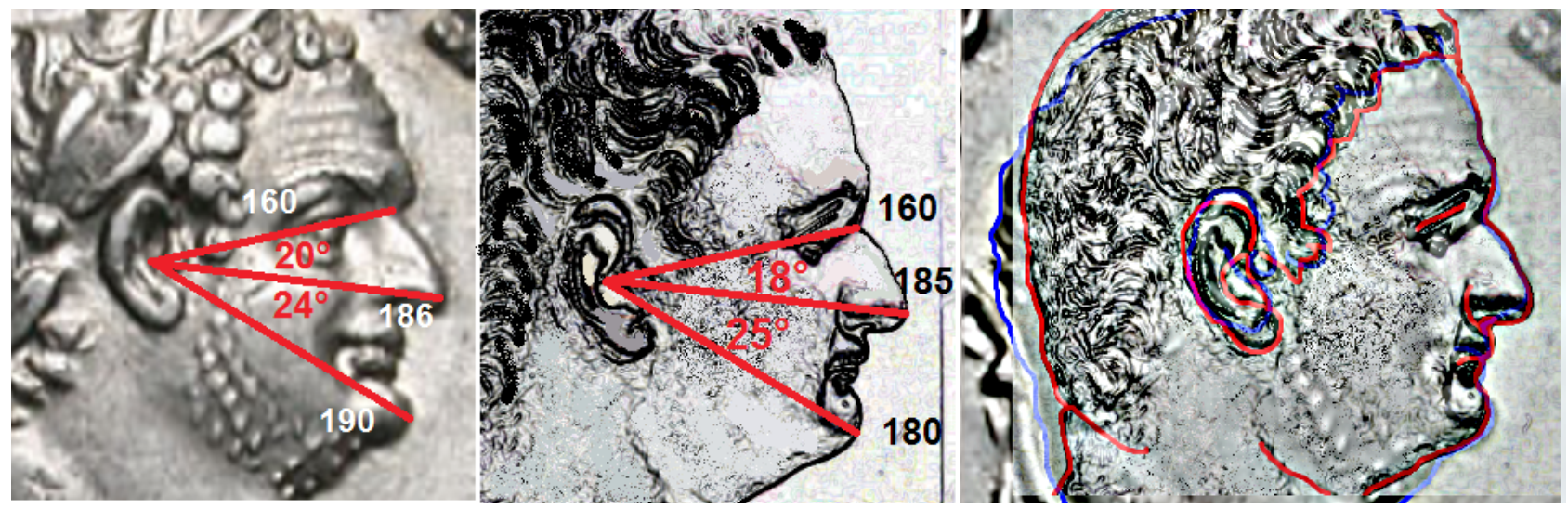

Figure 5. Profiles of coin and a drawing sketching the marble head of Titus found in Pantelleria. Lengths are given in pixels. Images of coin and bust are used here just for scientific and cultural purposes. (Courtesy images. Coin. AR Denarius. June-July 79 AD. Credit: Titus user for Wikipedia. Marble head: Schäfer, T. [7]).

Here data concerning Titus (see Figure 5). For the coin, ENB $=160, \mathrm{ETN}=186, \mathrm{ETC}=$ 190 (angles $20^{\circ}, 24^{\circ}$ ). Here the ratios ENB / ETN $=0.86, \mathrm{ETC} / \mathrm{ETN}=1.02$. For the marble head $\mathrm{ENB}=160, \mathrm{ETN}=185, \mathrm{ETC}=180$ (angles are $18^{\circ}, 25^{\circ}$ ). Here the ratios $\mathrm{ENB} /$ $\mathrm{ETN}=0.86, \mathrm{ETC} / \mathrm{ETN}=0.97$. Differences of the ratios are less than $5 \%$.

Let us conclude our comparisons with marble heads with Trajan emperor. Imperator Caesar Nerva Traianus Divi Nervae filius Augustus (18 September 53 - 8 August 117 AD) was emperor from 98 to 117 AD. Officially declared by the Senate optimus princeps, Trajan is remembered as a successful soldier-emperor who presided over the greatest military expansion in Roman history. He is also known for his philanthropic rule, implementing also social welfare policies. He was born in Italica, close to modern Sevilla, in the province of Hispania Baetica. Trajan's non-patrician family was of Italian and Iberian 
origin. Trajan rose to prominence during the reign of emperor Domitian. In September 96, Domitian was succeeded by Marcus Cocceius Nerva, an old and childless senator. After a brief and tumultuous year in power, culminating in a revolt by members of the Praetorian Guard, Nerva was compelled to adopt the more popular Trajan as his heir and successor. Nerva died on 27 January 98 and was succeeded by his adopted son without incident.

Trajan was the second of the Five Good Emperors. These Emperors were Nerva, Trajan, Hadrian, Antoninus Pius and Marcus Aurelius. This term was coined based on what Niccolò Machiavelli wrote in 1503.

As a civilian administrator, Trajan is best known for his extensive public building program, which reshaped the city of Rome and left numerous enduring landmarks such as Trajan's Forum, Trajan's Market and Trajan's Column. Deified by the Senate, his ashes were laid to rest under Trajan's Column.
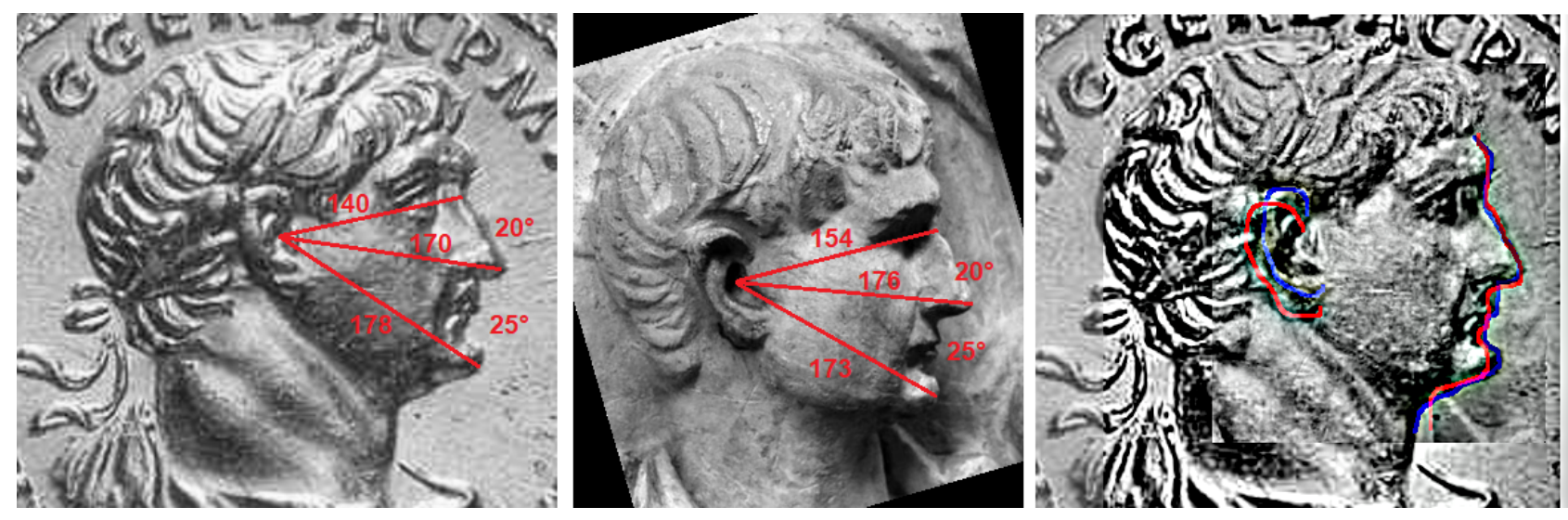

Figure 6. Profiles of coin and marble head of Trajan. Length are given in pixels. Images of coin and bust are used here just for scientific and cultural purposes. (Courtesy images. Coin. Credit: Classical Numismatic Group for Wikipedia. Marble head. Credit: http://www.trajans-column.org/).

For our analysis let us use a portrait from the Trajan Column and an Aureus struck 115 AD. Here the results from Figure 6.

For the coin, $\mathrm{ENB}=140, \mathrm{ETN}=170, \mathrm{ETC}=178\left(\right.$ angles $\left.20^{\circ}, 25^{\circ}\right)$. Here the ratios ENB $/$ $\mathrm{ETN}=0.82, \mathrm{ETC} / \mathrm{ETN}=1.05$. For the marble head $\mathrm{ENB}=154, \mathrm{ETN}=176, \mathrm{ETC}=173$ (angles are $20^{\circ}, 25^{\circ}$ ). Here the ratios ENB $/$ ETN $=0.87, E T C / E T N=0.98$. Differences of the ratios are less than $7 \%$. In this case, we find an enhancement of the chin. Angles are the same.

Let us consider a bearded emperor, Marcus Aurelius. 

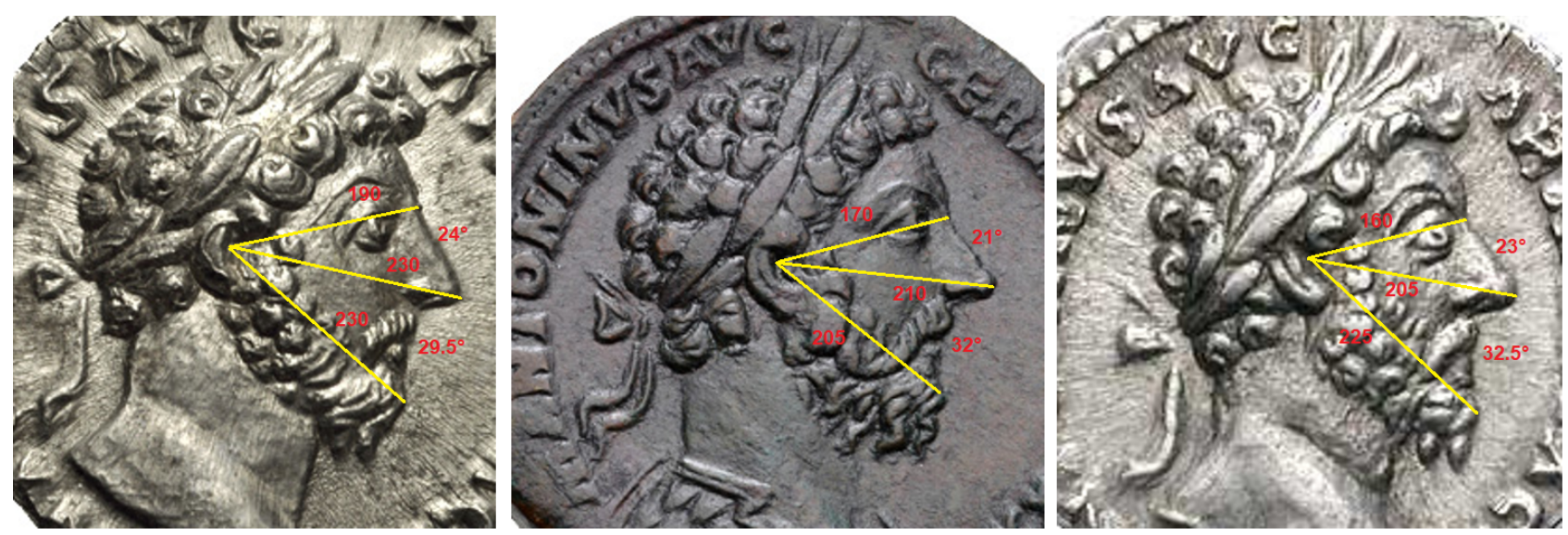

Figure 7. Profiles of coins of Marcus Aurelius (Left: AR Denarius. Rome mint. Struck AD 164. Middle:

Sestertius. Rome mint. Struck AD 177. Right: AR Denarius. Struck 165 AD. Images courtesy: Classical Numismatic Group, for Wikipedia).

Marcus Aurelius (26 April 121 - 17 March 180 AD) was Roman emperor from 161 to 180. He ruled with his adoptive brother, Lucius Verus, until Verus' death in 169, and with his son, Commodus, from 177 . He was the last successor of rulers traditionally known as the Five Good Emperors.

In the case of this emperor, I was not able to find a picture showing the profile of a statues, so let us investigate the coins. For the coin in the left panel, ENB $=190, E T N=230, E T C=$ 230 (angles $24^{\circ}, 29.5^{\circ}$ ). Here the ratios ENB $/$ ETN $=0.83$, ETC $/$ ETN $=1.0$. For the coin in the middle, $\mathrm{ENB}=170, \mathrm{ETN}=210, \mathrm{ETC}=205$ (angles $21^{\circ}, 32^{\circ}$ ). Here the ratios ENB $/$ $\mathrm{ETN}=0.81, \mathrm{ETC} / \mathrm{ETN}=0.98$. For the coin in the right panel, $\mathrm{ENB}=160, \mathrm{ETN}=205, \mathrm{ETC}$ $=225$ (angles $\left.23^{\circ}, 32.5^{\circ}\right)$. Here the ratios ENB $/$ ETN $=0.78$, ETC $/$ ETN $=1.09$. The fact that it is not easy to find the tip of the chin gives an uncertainty of $10 \%$ of the ratio ETC / ETN. The uncertainty of ENB / ETN is of about $4 \%$.

After the examples given above, we can estimate an uncertainty of the biometric ratios ENB / ETN , ETC / ETN of about $\pm 5 \%$. For the angles, it is of about $\pm 1^{\circ}$.

Let us conclude, after the proposed discussion, that, for the Roman leaders it was fundamental to show their faces on coins and statues in a truthful manner. As a consequence, each person in the Roman Empire was able to recognize them and have the authentication of them as the imperial authority, thanks to coins and statues. In a more symbolic manner, we can also imagine that the emperors used their face to guarantee the value of the Roman coinage too.

Other emperors are under study to see the evolution of the biometry in the profiles portrayed by coins and statues. 


\section{References}

[1] Sparavigna, A. C. (2018). Comparing the Profiles of Caesar's Heads Given by the Pantelleria Marble Bust and by a Coin of 44 BC (July 17, 2018). Zenodo, DOI: 10.5281/zenodo.1313808. Available at SSRN: https://ssrn.com/abstract=3224212

[2] Sparavigna, A. C. (2018). The Profiles of Caesar's Heads Given by Tusculum and Pantelleria Marbles (July 18, 2018). Zenodo, DOI: 10.5281/zenodo.1314696. Available at SSRN: https://ssrn.com/abstract=3224213

[3] Caesar's Career on Coins. Macquarie University, Sidney, Australia.

http://www.humanities.mq.edu.au/acans/caesar/Career_Coins.htm

[4] Sparavigna, A. C. (2013). Facial transformations of ancient portraits: the face of Caesar. arXiv preprint arXiv:1304.1972.

[5] Corazzi, G., \& Sparavigna, A. C. (2013). II Cesare Di Arles (Caesar at Arles). ARCHAEOGATE (2013). Available at SSRN: https://ssrn.com/abstract=2808313

[6] Corazzi, G., \& Sparavigna, A. C. (2013). The Rhone Caesar. Archeocommons, May 2013. Available at SSRN: https://ssrn.com/abstract=2749277

[7] Schäfer, T. (2004). Drei portrais aus Pantelleria: Caesar, Anonia Minor und Titus. In Caesar ist in der Stadt: die neu entdeckten Marmorbildnisse aus Pantelleria. HelmsMuseum. 